ВОРОНОВА Мария Викторовна - аспирант Института социологии Федерального научно-исследовательского социологического центра РАН (117218, Россия, г. Москва, ул. Кржижановского, 24/35, кopn. 5; tesamia@gmail.com; Silica2@yandex.ru)

\title{
О СОЦИАЛЬНЫХ ФАКТОРАХ АДАПТАЦИИ МИГРАНТОВ В ЗАРУБЕЖНЫХ ИССЛЕДОВАНИЯХ (США И ЕС)
}

Аннотация. Статья посвящена социологическому анализу социальных факторов адаптации мигрантов в современных исследованиях зарубежных ученых в США и ЕС. На основе основных факторов адаптации мигрантов автор рассматривает позитивный и негативный опыт ЕС и США в данной сфере. Автор приходит к выводу, что формирование позитивной адаптации мигрантов в принимающем обществе США и стран ЕС и выработка для них эффективной интеграционной политики происходит на местном (муниципальном, региональном) уровне. Такое положение заслуживает внимания при выработке эффективной интеграционной политики в России на современном этапе.

Ключевые слова: мигранты, США, ЕС, адаптация, интеграция, регионы, социальные факторы

И нтеграция мигрантов - не просто теоретически значимая задача, но и важная и актуальная практическая проблема, с которой сталкиваются многие современные общества - как развитые (США, страны ЕС и др.), так и развивающиеся (Россия, Турция и др.). В этой связи представляется актуальным анализ фактической практики современных обществ в области регулирования процесса социокультурной адаптации мигрантов. Обзор современных зарубежных исследований позволяет получить представление об институциональных механизмах (миграционное законодательство и политика, специальные социальные программы, информационная работа и т.д.), к которым прибегают различные страны для интеграции мигрантов. Рассмотрим опыт социокультурной интеграции мигрантов в двух крупнейших экономических регионах мира, являющихся точками притяжения для мигрантов и характеризующихся высокой культурной гетерогенностью, - США и ЕС.

$\boldsymbol{C Ш \boldsymbol { A }}$. История США традиционно характеризуется крайне высокой ролью, которую играют мигранты в жизни страны. Не случайно именно на примере иммигрантов в США были проведены первые научные исследования аккультурации [Thomas, Znaniecki 1918]. На всем протяжении XX в. характер и последствия миграционных потоков оставались в списке важнейших политических тем и были предметом множества исследований [Jimenez 2017; То Become... 2017]. До 1965 г. иммиграционное законодательство, выстроенное по квотному принципу, было ориентировано на принятие квалифицированных иммигрантов из европейских стран и членов из семей. Как следствие, более $70 \%$ всех легальных иммигрантов приезжали в США всего из трех стран: Великобритании, Ирландии и Германии [Hatton 2015: 349]. Принятие поправок к Акту об иммиграции сделало его менее дискриминационным и установило значительно более высокую квоту для иммигрантов из Восточного полушария (170 тыс. чел. в год). Следствием стало кардинальное изменение структуры миграционного потока и значительный рост численности мигрантов - выходцев из стран Азии и Латинской Америки. Это означало значительное увеличение доли мигрантов, характеризующихся существенно более низким социально-экономическим статусом (в сравнении с мигрантами из Европы) и существенно большей культурной дистанцией, что вызвало потребность в поиске институциональных механизмов интеграции. Несмотря на сохране- 
ние декларируемых культурных целей (иммигранты - важный источник культурного разнообразия страны), начало XXI в. характеризовалось изменением институциональных практик, фактически ухудшивших положение иммигрантов и возможности их адаптации. Изменившийся контекст (рост террористических угроз и усиление антииммигрантских настроений) привели к увеличению числа отказов в иммиграционных визах, насильственной депортации беженцев, перехвату в море судов с нелегальными мигрантами [Kerwin 2015]. Фактические практики органов иммиграционного регулирования, по сути, позволяют использовать естественные адаптационные сложности мигрантов (слабое знание языка, аккультурационный стресс, культурные различия и др.) для принятия решений об отказе в визах и депортации, не позволяя им получить доступ к существующим в США институтам социальной поддержки [Musalo 2015; Ribas 2016].

Современная миграционная политика администрации Трампа исходит из понимания, что «старая политика» перестала играть роль «плавильного котла», позволяющего ассимилировать внешних мигрантов, и способствует лишь росту мультикультурализма, числа нелегальных иммигрантов и этнически окрашенной преступности в стране 1 . Поэтому с 2018 г. введен запрет на иммиграцию из отдельных стран, возводится стена на границе с Мексикой, демонстрируется антииммигрантская риторика. Хотя США остается страной, декларирующей культурное разнообразие и открытость для иммигрантов, специалисты указывают на изменение контекста социокультурной адаптации. В отличие от середины XX в., современные макроуровневые условия для мигрантов характеризуются следующими проявлениями ${ }^{2}$ :

- ростом расслоения и имущественного неравенства в обществе, нехваткой рабочих мест и ростом требований к квалификации и образованию. Результатом становится недоступность для мигрантов образа жизни американского среднего класса, разочарование и формирование «оппозиционной культуры»;

- «концентрацией бедности» и формированием достаточно замкнутых бедных городских сообществ, состоящих преимущественно из мигрантов. Тем самым формируется локальный контекст, усложняющий адаптацию, порождающий маргинализацию и отчуждение мигрантов в принимающем обществе;

- постоянным притоком новых мигрантов, насыщающих локальные сообщества вынужденными этническими коммуникациями и препятствующими их ассимиляции. Иначе говоря, доступность страны для мигрантов, в т.ч. нелегальных, приводит к увеличению этнической плотности в местах их проживания и, как следствие, к сохранению значительного числа элементов этнической культуры в повседневной жизни.

Исследования, поведенные в США, показывают неадекватность теорий ассимиляции, исходящих исключительно из индивидуальной перспективы, и демонстрируют принципиальную значимость таких макроуровневых факторов адаптации мигрантов, как 1) особенности культуры страны происхождения, 2) особенности культуры принимающего общества, а также локальных сообществ иммигрантов. При этом страна происхождения является более важным фактором адаптации, чем страна пребывания. Значительное разнообразие контекстов социокультурной адаптации и большое число стран - источников миграции делают практически невозможным обобщающий анализ социо-

${ }^{1}$ Новая иммиграционная политика Трампа. Доступ: https://business-visa-usa.ru/blog/immigration/ item/128-novaya-immigratsionnaya-politika-trampa (проверено 18.09.2018).

2 Новый формат иммиграционной политики США в 2018 году. Доступ: https://business-visausa.ru/blog/immigration/item/158-novyj-format-immigratsionnoj-politiki-ssha-v-2018-godu (проверено 18.09.2018). 
культурной адаптации в таких гетерогенных странах, как США. Большинство эмпирических исследований ограничиваются отдельными этническими группами или регионами. Так, в книге мексиканских социологов, посвященной интеграции мигрантов из Мексики в Калифорнии, проводится подробный анализ факторов, влияющих на ее успешность, в т.ч. политических и институциональных [Alarcon, Escala, Odgers 2016]. Они, в частности, проанализировали нормативно-правовую среду и выявили, что только на уровне штатов каждый год принимается более 200 законов и решений, напрямую затрагивающих интересы мигрантов в различных областях - от образования и здравоохранения до получения водительских прав [Alarcon, Escala, Odgers 2016: 186]. По сути, это подтверждает гипотезу о важной роли региональных различий в формировании условий адаптации в гетерогенных обществах. Авторы отмечают, что, несмотря на рост антииммигрантских настроений в обществе, СМИ и политическом дискурсе, в правовой системе большинства штатов (за исключением особо консервативных, таких как Аризона) подобная тенденция не наблюдается. В Калифорнии, в которой доля иммигрантов из Мексики максимальна, их интересы защищаются достаточно большим числом местных политических лидеров, имеющих латиноамериканские корни [Alarcon, Escala, Odgers 2016: 187].

Более глубокий анализ показал, что на условия адаптации мигрантов из Мексики действуют разнонаправленные силы, отражающие конфликт интересов различных групп акторов: службы иммиграции, полиции, муниципалитетов, общественных организаций. Например, иммиграционная служба использует соглашения с местной полицией для выявления нелегальных мигрантов и их депортации. Правозащитные организации утверждают, что такое сотрудничество способствует росту напряженности среди иммигрантов, которые опасаются, что их могут выдворить из страны даже за мельчайшие правонарушения. Вместе с тем многие муниципалитеты, которые обладают в США значительными полномочиями, не подписывают подобные соглашения либо принимают внутренние законы, которые запрещают полицейским департаментам чрезмерное усердие в реализации иммиграционного законодательства [Alarcon, Escala, Odgers 2016: 192]. Таким образом местные власти, правозащитные НКО и локальные сообщества противодействуют негативным факторам адаптации, действующим на национальном уровне, оказывая положительное влияние на интеграцию иммигрантов.

Региональные программы и нормативные акты, действующие в рамках других институтов, также имеют прямые и, что важно, разнонаправленные последствия для адаптации иммигрантов. Например, действующая в Калифорнии программа финансовой помощи легальным мигрантам (CAPI) была приостановлена губернатором А. Шварценеггером из-за бюджетных ограничений, что негативно сказалось на доступности социальных услуг. С другой стороны, высокую эффективность показала окружная программа «Против преступлений на почве ненависти» (Program against Hate Crimes), финансирующая организации, которые занимаются мониторингом таких преступлений, а также обучением их жертв [Alarcon, Escala, Odgers 2016: 193]. Реализация этой программы способствовала защите прав меньшинств.

Одним из важнейших универсальных механизмов социальной адаптации мигрантов в США являются программы обучения языку ( $E S L$, английский как второй язык), действующие в т.ч. для взрослых. Несмотря на наличие общенациональной инициативы, ее фактическая реализация, а зачастую и финансирование зависят от действий властей штата. Эволюция политического процесса как на федеральном уровне, так и на уровне штатов характери- 
зуется периодическим усложнением или, наоборот, либерализацией доступа иммигрантов к образовательным и другим социальным услугам. Это показывает важность учета динамической природы внешней среды и изменений институциональных условий не только в долгосрочной, но и в краткосрочной перспективе. Аналогичные амбивалентные и разнонаправленные факторы действуют и в рамках других институтов, таких как рынок труда, экономическая деятельность, оформление документов, социальное обеспечение. Общий вывод, который может быть сделан из приведенного анализа, заключается в признании факта разнородности действующих сил, акторов, определяющих условия для интеграции иммигрантов, а также зачастую разнонаправленный характер инициатив, действующих на федеральном, региональном и муниципальном уровне.

Обоснованность проведения различия между национальным и местным уровнем в формировании среды социокультурной адаптации подтверждается и в сравнительном исследовании голландских специалистов, сравнивших интеграцию иммигрантов в двух европейских и двух американских мегаполисах [De Graauw, Vermeulen 2016]. Авторы пришли к выводу об исключительной значимости именно местного уровня, городского политического процесса и участия в нем иммигрантов. Если говорить более конкретно, они называют 3 фактора городских политических институтов, способствующих позитивной адаптации иммигрантов: 1) левое правительство; 2) значимый вес иммигрантского электората и их представленность в органах власти; 3) развитую инфраструктуру самоорганизации местных сообществ и представительство коллективных интересов иммигрантов в политическом процессе. Как показало исследование, значимость этих факторов такова, что городская миграционная политика в США может способствовать эффективной интеграции, даже если на национальном или региональном уровнях условия внешней среды неблагоприятны для мигрантов. Отметим, что подобная роль местных сообществ и органов власти обеспечивается развитой системой местного самоуправления, характерной для западных стран, и высоким уровнем самостоятельности и ресурсообеспеченности муниципалитетов.

Eвропейский союз. ЕС, как и США, является точкой притяжения для мигрантов из различных регионов мира, но особенно из стран Восточной Европы, Ближнего Востока и Северной Африки. Современный период характеризуется значительным ростом потока мигрантов и усилением проблемы их интеграции, что выражается в растущем числе публикаций и активном обсуждении иммиграционной политики ${ }^{1}$ [Schinkel 2017; Mainstreaming Integration... 2018].

В острую фазу миграционного кризиса ЕС вступил примерно с 2014 г., когда из-за действий ИГИЛ (запрещенная в России террористическая организация) и масштабных военных действий на территории Сирии и Ирака резко выросло число беженцев. Число лиц, пытающихся получить убежище в Европе, превысило отметку в 1,3 млн за 2015 г. только официальных обращений [Constant, Zimmermann 2016]. Основными пунктами назначения беженцев стала Германия (66\% всех обращений в 2016 г.). После 2015 г. растущий миграционный кризис повысил риски распада ЕC, а также риски роста терроризма и дестабилизации общественной безопасности. Кроме того, на общеевропейском уровне разработанные программы миграционной политики не предусматривают никакой адаптации или интеграции внешних мигрантов. Это грозит странам ЕС изменением европейской идентичности, против чего выступают большинство политиков,

\footnotetext{
${ }^{1}$ Indicators of Immigrant Integration 2015. - Settling In. 2015. Paris: OECD Publishing. 348 p. URL: http:// www.oecd.org/els/indicators-of-immigrant-integration-2015-settling-in-9789264234024-en.htm (accessed 18.09.2018).
} 
а также многие оппозиционные общественные силы в странах ЕС [Кравченко 2016]. Европа, реализуя успешные программы ассимиляции на индивидуальном уровне, оказалась совершенно не готова к массовой интеграции мигрантов. Этот вывод подтверждается и европейскими исследователями [Constant, Zimmermann 2016]. Проблема соотношения интеграционных усилий на национальном и муниципальном уровне рассматривалась в исследовании Д. Гебхарта. Признавая, что города обладают значительной автономией в формировании политики интеграции, он, тем не менее, отмечает, что в последние годы с городскими программами начинают конфликтовать крупномасштабные государственные программы. Исследуя этот феномен на материале Германии, Нидерландов и Швеции, он показывает, что роль городов снижается, уступая место крупным ресурсообеспеченным программам изучения языка, информирования о принимающих обществах, а также профессиональной ориентации [Gebhardt 2016]. Автор заключает, что государство становится центральным актором в интеграционных усилиях в Европе.

Изменение подхода к интеграции отражает возросшую остроту миграционного кризиса в Европе и необходимость масштабных усилий. Но разница между национальным и муниципальным уровнем заключается не только в масштабах, но и в идеологии. Если городские программы традиционно разрабатывались с учетом потребностей самих мигрантов и отличались большей индивидуализацией, то общеевропейские программы сместили фокус внимания на обязанности мигрантов, реализуя подход, который в терминах теоретической модели социокультурной адаптации мигрантов Ю. Ким можно охарактеризовать как усиление «требований конформизма» [Kim 1988]. По очевидным причинам мигранты из менее развитых стран сталкиваются с серьезными трудностями при трудоустройстве в странах Западной Европы с ее высококонкурентным и требовательным рынком рабочей силы. Финский специалист М. Сарвимяки проанализировал несколько десятков исследований, посвященных конкретным практикам и программам интеграции мигрантов на европейском рынке труда [Sarvimäki 2017]. Он рассмотрел эффективность четырех типов программ: по обучению, помощи в поиске работы, субсидиям на заработную плату для мигрантов и субсидиям на трудоустройство мигрантов в бюджетных организациях. Автор определяет реальную эффективность только одного типа институциональных механизмов, а именно субсидий на заработную плату. По-видимому, этот тип поддержки обеспечивает экономическую самостоятельность и относительную свободу выбора рабочего места для мигрантов, снижая стресс от материальной неустроенности и зависимости от конкретного работодателя, и одновременно включает его в систему социальных отношений с принимающим обществом.

Исследование голландских социологов под редакцией П. Шольтена и Я. ван Брейгеля является еще одной попыткой проанализировать и осмыслить последние тенденции в управлении процессами адаптации и интеграции мигрантов в Европе [Mainstreaming Integration... 2018]. Авторы отмечают, что новая волна иммиграции привела к значительному росту этнокультурного разнообразия в ЕС, в результате чего стало невозможно эффективно работать с отдельными этническими группами. Реакцией на новую реальность стал рост антииммигрантских настроений и смена интеграционной политики на основе идей мультикультурализма на модель социокультурной ассимиляции. Подобно М. Сарвимяки, авторы делают вывод, что специализированным программам интеграции пришла на смену общеевропейская политика, пронизывающая различные секторы и уровни управления [Mainstreaming Integration... 2018: 4]. В рамках новой политики реализуются программы, основанные на общих 
принципах и подходах и отказывающиеся от учета специфики отдельных этнокультурных групп мигрантов. В основе этих принципов лежит не столько централизация управления интеграционными процессами, сколько координация множества разноуровневых программ на основе общих принципов и отказа от установления специализированных целевых ориентиров интеграции мигрантов для конкретных этнических групп.

Критический анализ интеграционной политики в странах $\mathrm{EC}$, прежде всего в Великобритании, Испании, Франции, Нидерландах и Польше, позволил авторам сделать вывод, что универсальная модель реализована в Европе лишь частично. На национальном уровне, наоборот, из-за недостатка компетенций наблюдается неспособность решить проблему этнокультурного разнообразия. В свою очередь, локальный уровень более успешно решает эту задачу за счет программ, направленных на формирование общей идентичности и инклюзивности, прежде всего в крупных мегаполисах стран ЕС. О некоторых результатах современной интеграционной политики ЕС можно судить по периодически публикуемым аналитическим отчетам ОЭСР. Последний опубликованный отчет за 2015 г. позволяет сделать некоторые выводы о социокультурной адаптации внешних мигрантов ЕС (на которых в основном и ориентирована интеграционная политика) по ряду следующих макроуровневых показателей управления [Mainstreaming Integration... 2018: 239].

1. Рынок труда. Уровень трудоустройства мигрантов ниже, чем местного населения, и составляет 54\%, уровень безработицы приблизительно в 2 раза выше; мигрантам с более высоким образованием сложнее найти работу, чем мигрантам с низким образованием, средний уровень «чрезмерной квалификации» составляет $44 \%$, что более чем в 2 раза выше, чем среди европейцев.

2. Образование. Значительная часть мигрантов испытывают дефицит базовых навыков: в возрасте 18-24 лет их доля составляет 18\%, что в 4,5 раза больше, чем у европейцев. Только 3 страны ЕС (Великобритания, Ирландия и Люксембург) смогли достичь цели ЕС по доведению доли мигрантов в возрасте 30-34 лет, имеющих высшее образование, до $40 \%$.

3. Здравоохранение и условия жизни. Доход мигрантов ниже дохода местных жителей, 39\% мигрантов живут в бедности; вероятность обзавестись своим домом среди мигрантов в 3 раза ниже, чем среди местных жителей; мигранты считают себя более здоровыми, чем европейцы.

4. Гражданский статус и дискриминация. В голосовании на национальных выборах принимали участие 7 из 10 мигрантов, получивших европейское гражданство, что приблизительно на $10 \%$ меньше, чем среди европейцев, имеющих право голоса. Приблизительно четверть мигрантов сообщают, что они испытывали дискриминацию из-за своего происхождения, причем уровень воспринимаемой дискриминации оказался наименьшим в Скандинавских странах и Люксембурге, а максимальным - в Греции и Австрии.

Таким образом, как в США, так и в странах ЕС современная миграционная ситуация рассматривается как более острая, чем раньше, а значительное число слабо интегрированных мигрантов свидетельствует о проблемах в социокультурной адаптации. Рост антииммиграционных настроений характерен для обоих макрорегионов, что приводит к общему выводу, что в основе миграционной политики любого государства в первую очередь должны лежать национальные интересы и только затем уже - многочисленные обязательства в рамках международных договоров.

\section{Список литературы}

Кравченко Л.И. 2016. Миграционный кризис в Европе. - Центр Сулакшина 
(Центр научной политической мысли и идеологии). 21.03.2016. Доступ: http:// rusrand.ru/analytics/migracionnyy-krizis-v-evrope (проверено 18.09.2018).

Alarcon R., Escala L., Odgers O. 2016. Making Los Angeles Home: The Integration of Mexican Immigrants in the United States. Oakland: University of California Press. 281 p.

Constant A.F., Zimmermann K.F. 2016. Toward a New European Refugee Policy that Works. Maastricht: UNU-MERIT Working Papers. 2016-062. 20 p.

De Graauw E., Vermeulen F. 2016. Cities and the Politics of Immigrant Integration: a Comparison of Berlin, Amsterdam, New York City, and San Francisco. - Journal of Ethnic and Migration Studies. Vol. 42. P. 989-1012.

Gebhardt D. 2016. When the State Takes over: Civic Integration Programmes and the Role of Cities in Immigrant Integration. - Journal of Ethnic and Migration Studies. Vol. 42. Iss. 5. P. 742-758.

Hatton T.J. 2015. United States Immigration Policy: The 1965 Act and Its Consequences. - Scandinavian Journal of Economics. Vol. 117. P. 347-368.

Jimenez T. 2017. The Other Side of Assimilation: How Immigrants Are Changing American Life. Oakland: University of California Press. 296 p.

Kerwin D. 2015. The US Refugee Protection System on the $35^{\text {th }}$ Anniversary of the Refugee Act of 1980. - Journal of Migration and Human Security. Vol. 3. P. 205-254.

Kim Y.Y. 1988. Communication and Cross-Cultural Adaptation: An Integrative Theory. Clevedon, UK: Multilingual Matters. 232 p.

Mainstreaming Integration Governance: New Trends in Migrant Integration Policies in Europe (ed. by P. Scholten, I. van Breugel). 2018. Cham: Palgrave Macmillan. 268 p.

Musalo K. 2015. The Evolving Refugee Definition: How Shifting Elements of Eligibility Affect the Nature and Focus of Expert Testimony in Asylum Proceedings. - African Asylum at a Crossroads: Activism, Expert Testimony, and Refugee Rights. Ohio: Ohio University Press. Chapter 3. P. 75-101.

Ribas V. 2016. On the Line: Slaughterhouse Lives and the Making of the New South. Oakland: University of California Press. 272 p.

Sarvimäki M. 2017. Immigrant Integration: Policy. Kiel: Kiel Institute Summer School on Economic Policy. 41 p. URL: www.aalto-econ.fi/sarvimaki/integration_policy.pdf (accessed 12.07.2018).

Schinkel W. 2017. Imagined Societies: A Critique of Immigrant Integration in Western Europe. Cambridge: Cambridge University Press. 34 p.

Thomas W.I., Znaniecki F. 1918. The Polish Peasant in Europe and America: Monograph of an Immigrant Group. Vol. 1. Primary Group Organization. Boston: The Gorham Press. 604 p.

To Become an American: Immigrants and Americanization Campaigns of the Early Twentieth Century (ed. by L.A. Hahner). 2017. East Lansing: Michigan State University Press. 192 p.

\section{SOCIAL FACTORS OF ADAPTATION OF MIGRANTS IN FOREIGN INVESTIGATIONS IN THE USA AND THE EU}

Abstract. The article is devoted to the sociological analysis of social factors of migrants' adaptation in modern researches of foreign scientists in the USA and the EU. The article discusses the positive and negative experience of the EU and the US in this area, based on the main factors of migrants' adaptation. The author concludes that the formation of positive migrants' 
adaptation in the host society of the United States and EU countries, and the development of effective integration policy for them takes place at the local (municipal, regional) level. This situation deserves attention in the development of an effective integration policy in Russia at the present stage.

Keywords: migrants, USA, EU, adaptation, integration, regions, social factors

\section{УДК 94 (518)}

ЦЫБЕНОВ Базар Догсонович - кандидат исторических наук, доцент; старший научный сотрудник отдела истории и культуры Центральной Азии Института монголоведения, буддологии и тибетологии СО РАН (670047, Россия, Республика Бурятия, г. Улан-Удэ, ул. Сахьяновой, 6; bazar75@ mail.ru)

\section{РАЗВИТИЕ СЕЛЬСКОГО ХОЗЯЙСТВА ДАУРСКОГО АВТОНОМНОГО ХОШУНА МОРИН-ДАВА В 1980-1990-х гг.}

Аннотация. В статье рассматривается развитие основных отраслей сельского хозяйства даурского автономного хошуна Морин-Дава в период социально-экономических реформ в КНР. Автор уделяет особое внимание становлению и развитию механизированной земледельческой площадки Каядурбэн в первой половине 1980-х гг., а также изучает механизацию сельского хозяйства, развитие животноводства и подсобного хозяйства дауров.

Ключевые слова: дауры, автономный хошун Морин-Дава, сельское хозяйство, реформы, земледелие, животноводство, урожайность, доходы крестьян

$\Gamma$ оды реформ в КНР стали той прочной основой, которая позволила стране в кратчайшие сроки выйти на ведущие мировые позиции. Одним из удачных решений китайского руководства в тот период было реформирование сельского хозяйства. В нашей работе мы попытались рассмотреть развитие сельского хозяйства даурского автономного хошуна Морин-Дава в 80-90-х гг. XX в. Изучение данной проблемы актуально, поскольку в российской исторической науке она ранее не рассматривалась. Даурский автономный хошун является аграрным регионом, и обращение к сельскому хозяйству во многом поможет изучению истории развития национальной автономии дауров.

В конце 70-х - начале 80-х гг. XX в. в китайском обществе начались позитивные перемены. Выражались они в осуждении леворадикального курса; упразднении ревкомов; реабилитации лиц, подвергшихся гонениям по ложным обвинениям в годы «культурной революции» [Цыбенов 2018: 190-191]. Хулун-Буирский аймак, включая даурский автономный хошун Морин-Дава, был возвращен в состав Внутренней Монголии. После хошунного съезда, состоявшегося в июне 1980 г., были реабилитированы более 6 тыс. чел. Несмотря на потери в годы «культурной революции», даурские национальные кадры продолжали составлять $35 \%$ всех кадровых работников. Даурами были и избранные в 1982 г. секретарь хошунного парткома Амгулан и председатель хошуна Тун Чин.

Одним из главных вопросов, стоявших перед руководством хошуна, было своевременное включение в набирающую обороты экономическую реформу. В 1983 г. площадь обрабатываемых земель всего хошуна приближалась к 1 млн 80 